УДК 621.311.001.63

\title{
ТЕХНИКО-ЭКОНОМИЧЕСКОЕ ОБОСНОВАНИЕ ВОЗМОЖНОСТИ УСТАНОВКИ АККУМУЛЯТОРНОЙ БАТАРЕИ БОЛЬШОЙ МОЩНОСТИ В ЭЛЕКТРИЧЕСКОЙ СЕТИ
}

Андрианова Людмила Прокопьевна д-р техн. наук, профессор Павлова Зухра Хасановна д-р техн. наук, профессор Рябишина Лилия Амировна канд. техн. наук, доцент Хакимьянов Марат Ильгизович д-р техн. наук, профессор Хазиева Регина Тагировна канд. техн. наук, доцент ФГБОУ ВО Уфимский государственный нефтяной технический университет

Аннотация. В статье рассматривается возможность установки аккумуляторной батареи большой мощности (АББМ) в электрической сети для увеличения пропускной способности сети и устойчивости работы межсистемной связи. При проведении технико-экономического обоснования рассмотрены два варианта усиления сети: первый со строительством новой ВЛ 220 кВ и установкой двух элегазовых выключателей 220 кВ на примыкающих подстанциях; второй с установкой АББМ и элегазового выключателя на одной из подстанции данной межсистемной связи. Для данных вариантов рассчитаны капитальные вложения, издержки на ремонт и обслуживание электрооборудования, дисконтированные затраты. По результатам расчетов установлено, что минимум дисконтированных затрат имеет место при строительстве новой ВЛ 220 кВ, и установка АБММ в исследуемой электрической сети нецелесообразна.

Ключевые слова: Электрическая сеть, технико-экономическое обоснование, строительство воздушной линии 220 кВ, установка аккумуляторной батареи большой мощности, капитальные вложения, ежегодные издержки на ремонт и обслуживание, дисконтированные затраты. 


\title{
FEASIBILITY STUDY POSSIBILITIES OF INSTALLING A HIGH-POWER BATTERY IN THE ELECTRICAL NETWORK
}

\author{
Andrianova Lyudmila Prokofievna \\ Pavlova Zuhra Khasanovna \\ Ryabishina Liliya Amirovna \\ Khakimjanov Marat Ilgizovich \\ Khazieva Regina Tagirovna
}

\begin{abstract}
The article discusses the possibility of installing a high-power battery $(\mathrm{ABB})$ in the electric network to increase the network capacity and stability of intersystem communication. During the feasibility study, two options for strengthening the network were considered: the first with the construction of a new $220 \mathrm{kV}$ overhead line and the installation of two $220 \mathrm{kV}$ gas switches at adjacent substations; the second with the installation of an ABB AND a gas switch at one of the substations of this intersystem connection. Capital investments, repair and maintenance costs for electrical equipment, and discounted costs are calculated for these options. Based on the results of calculations, it is established that the minimum discounted costs occur during the construction of a new $220 \mathrm{kV}$ overhead line, and the installation of ABMM in the studied electrical network is impractical.
\end{abstract}

Keywords: Electrical network, feasibility study, construction of a $220 \mathrm{kV}$ overhead line, installation of a high-capacity battery, capital investment, annual repair and maintenance costs, discounted costs.

В статье рассматривается электрическая сеть с двумя энергосистемами, связь между которыми реализована двумя воздушными линиями ВЛ 500 кВ и одной воздушной линией ВЛ 220 кВ (рис. 1).

Амплитуда нерегулярных колебаний перетока по межсистемной связи составляет $\Delta P_{\text {нк }}=240$ МВт. В послеаварийном режиме при отключении одной ВЛ 500 кВ максимально допустимый переток по сечению существенно снижается.

Для увеличения пропускной способности и устойчивости работы межсистемной связи предусматривается установка аккумуляторной батареи большой мощности (АББМ) [1-3]. 


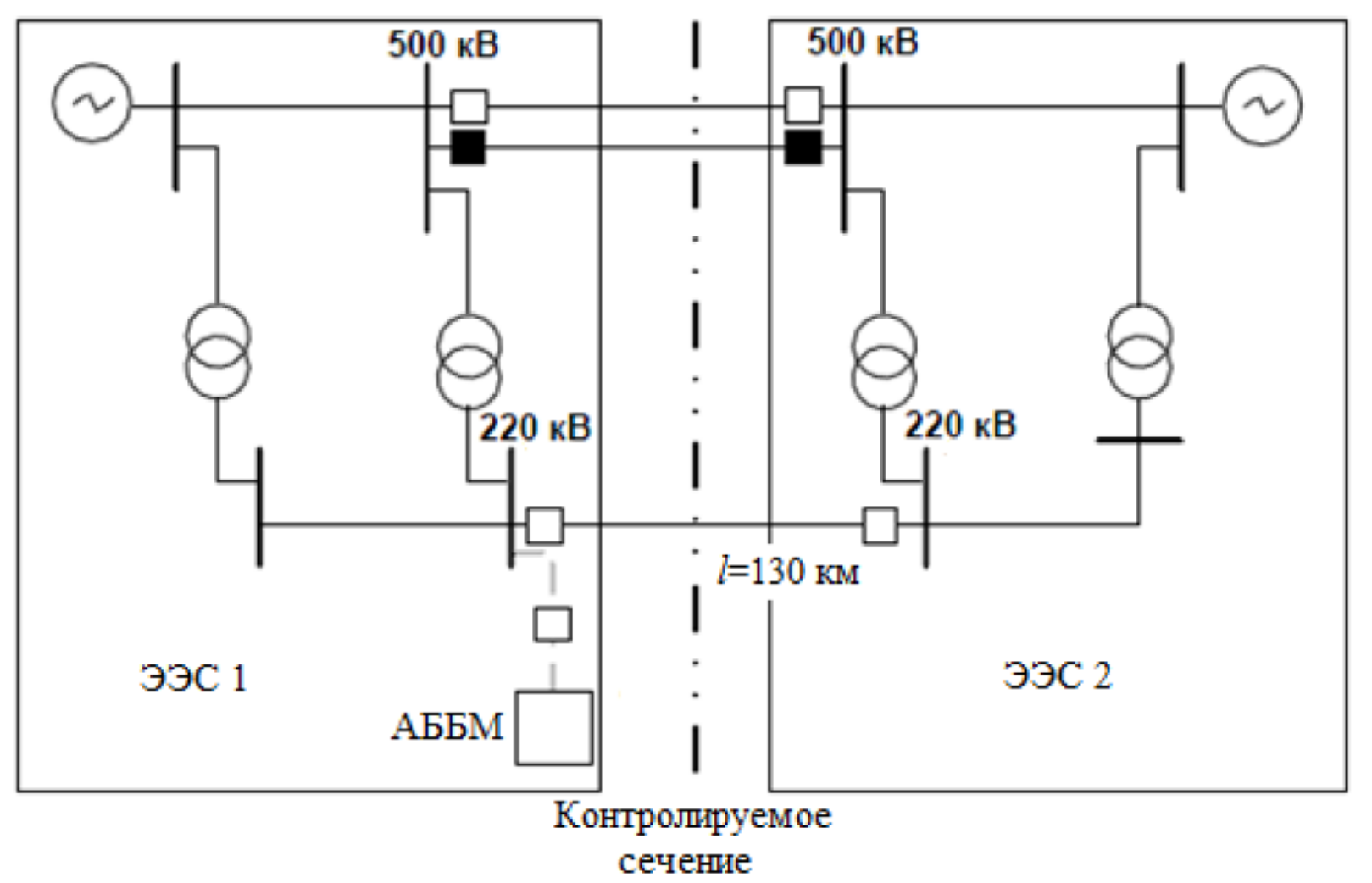

\section{Рис. 1. Схема электрической сети}

Для проверки возможности установки АББМ проводится техникоэкономическое сравнение двух вариантов усиления сети [6]:

1) Вариант 1: Строительство второй ВЛ 220 кВ с проводами АС-240 длиной $l=130$ км, включая установку двух элегазовых выключателей 220 кВ на примыкающих подстанциях (ПС);

2) Вариант 2: Установка аккумуляторной батареи большой мощности (АББМ) для покрытия нерегулярных колебаний в течение суток мощностью $P_{\text {АББм }}=130$ МВт и элегазового выключателя на одной из ПС данной межсистемной связи.

Характер нерегулярных колебаний определяет продолжительность беспрерывного разряда АББМ - не более $\Delta t=0,2$ ч, то есть,

$$
P_{\text {АББм }} \cdot \Delta t=130 \cdot 0,2=26 \mathrm{MBT}^{\circ}{ }^{\circ} .
$$

\section{Общие данные для проведения технико-экономического сравнения} вариантов

При технико-экономическом обосновании электросетевых объектов используется формула приведенных (дисконтированных) затрат, как сумма 
капиталовложений $K$ и издержек $И$ в общем случае за некоторый расчетный период времени $T_{\text {расч. }}$

Альтернативные варианты при обосновании электросетевых объектов сравниваются по значению дисконтированных затрат за расчетный период времени. Выбор предпочтительного варианта ведется по их минимуму. За расчетный период времени рекомендуется принимать минимальный расчетный срок службы 30 лет, соответствующей минимальному расчетному сроку службы основного оборудования подстанции - силовых (авто)трансформаторов, оборудования открытого распределительного устройства (ОРУ) 110 кВ и выше [3].

Согласно НД «Методические указания по технико-экономическому обоснованию электросетевых объектов. Эталоны обоснований» [6] техникоэкономическое сравнение электросетевых объектов выполняется в ценах 2000 г. Капитальные вложения на электросетевые объекты оцениваются по укрупненным показателям стоимости [4], где они приведены в базисном уровне цен (по состоянию на 01.01.2000 г.) и не включают НДС.

Определение стоимости сооружения объектов в региональном разрезе осуществляется с применением коэффициентов, учитывающих региональноклиматические условия строительства и сейсмичность.

Отчисления на ремонт и обслуживание соответственно принимаются равными $[4,6]: 0,4$ и 0,4 \% для ВЛ; 2,9 и 2,0 \% для оборудования подстанции; $5 \%$ для АББМ.

Стоимость объекта-аналога АББМ составляет $k_{\text {АББм}}=30$ млн. руб./МВт·ч в ценах 2010 г. и 8,5 млн. руб./МВт·ч в ценах 2000 г.

Ставка дисконтирования принимается на уровне нормы доходности инвестированного капитала для расчета тарифов на услуги по передаче электроэнергии в единой национальной электрической сети (ЕНЭС), без учета инфляции (ставка дисконтирования нетто). Ставка дисконтирования $E_{\text {н.п. }}=0,06$.

\section{Расчет по варианту 1.}

Строительство одноцепной ВЛ 220 кВ с проводами АС-240 длиной $l=130$ км, с установкой двух элегазовых выключателей 220 кВ.

\section{Капиталовложения на строительство ВЛ 220 кВ}

Капиталовложения на строительство одноцепной ВЛ 220 кВ:

$$
K_{\text {ВЛ }}=k_{\text {ВЛ }} \cdot l_{1} \cdot k_{\text {стр }} \cdot k_{\text {рег }} \cdot k_{\mathrm{c}},
$$

где $k_{\mathrm{B} л}-$ удельные капиталовложения на ВЛ, $k_{\mathrm{B} л}=1,485$ млн. руб. / км $[4]$

$$
l_{1}-\text { длина ВЛ } 220 \text { кВ, } l_{1}=130 \text { км; }
$$


$k_{\text {стр }}-$ коэффициент, учитывающий затраты, сопутствующие строительству: временные здания и сооружения, строительный контроль и др., $k_{\text {стр }}=1,24[4]$;

$k_{\text {рег }}, k_{\mathrm{c}}$ - региональные коэффициенты удорожания строительства, и в сейсмических районах соответственно, $k_{\text {рег }}=1,09 ; k_{\mathrm{c}}=1,0$ [4])

$K_{\text {Вл }}=1,485 \cdot 130 \cdot 1,24 \cdot 1,09 \cdot 1,0=260,92$ млн. руб.

Капиталовложения на установку элегазового выключателя

$$
K \mathrm{~B}=n_{\mathrm{B}} \cdot k_{\mathrm{B}} \cdot k_{\mathrm{cтp}} \cdot k_{\text {рег }} \cdot k_{\mathrm{c}}=1 \cdot 14,698 \cdot 1,236 \cdot 1,0 \cdot 1,0=18,17 \text { млн. руб. }
$$

где $n_{\mathrm{B}}-$ количество дополнительных выключателей, $n_{\mathrm{B}}=1$;

$k_{\mathrm{B}}-$ удельные капиталовложения на дополнительный элегазовый выключатель, $k_{\mathrm{B}}=14,698$ млн. руб. [4];

$k_{\text {стр }}-$ коэффициент, учитывающий затраты, сопутствующие строительству: временные здания и сооружения, строительный контроль и др., $k_{\text {стр }}=1,236[4]$;

$k_{\text {рег }}, k_{\mathrm{c}}$ - региональные коэффициенты удорожания строительства и в сейсмических районах соответственно, $k_{\text {per }}=1,0 ; k_{\mathrm{c}}=1,0$ [4]).

$K_{\text {в }}=1 \cdot 14,698 \cdot 1,236 \cdot 1,0 \cdot 1,0=18,17$ млн. руб.

\section{Ежегодные издержки на ремонты и обслуживание ВЛ и ПС}

Ежегодные затраты на ремонты и обслуживание объектов генерации регламентируются Постановлением Правительства РФ от 13.04.2010 № 238 в ценах на 01.01.2010. Ежегодные издержки на ремонты и обслуживание элементов электрической сети определяются в виде отчислений от соответствующих капитальных вложений [6].

Результаты расчетов издержек на ремонт и обслуживание ВЛ и ПС приведены в таблице 1 .

Таблица 1

Издержки на ремонты и обслуживание ВЛ И ПС

\begin{tabular}{|c|c|c|}
\hline Издержки & ВЛ & $\Pi \Pi$ \\
\hline $\begin{array}{l}\text { Издержки на ремонт ВЛ, } \\
И_{\text {рем.ВЛ }}, \text { млн. руб. }\end{array}$ & $И_{\text {рем.вл }}=0,004 \cdot 260,9=1,04$ & $И_{\text {рем.ПС }}=0,029 \cdot 18,7=0,54$ \\
\hline $\begin{array}{l}\text { Издержки на обслуживание } \\
\text { ВЛ, } И_{\text {рем.ВЛ }, \text { млн. руб. }}\end{array}$ & Йбсл..вл $_{\text {ов }}=0,004 \cdot 260,9=1,04$ & $И_{\text {обсл..ПС }}=0,02 \cdot 18,7=0,37$ \\
\hline $\begin{array}{l}\text { Ежегодные издержки на } \\
\text { ремонт и обслуживание, } \\
\text { млн. руб. }\end{array}$ & 2,08 & 0,91 \\
\hline
\end{tabular}


Суммарные годовые издержки на ремонт и обслуживание ВЛ и ПС составляют

$$
И=И_{\mathrm{Bл}}+И_{\Pi \mathrm{C}}=2,08+0,91=2,99 \text { млн. руб. }
$$

Дисконтированные затраты по варианту 1

Дисконтированные затраты определяют по формуле

$$
3_{i}=K+И \cdot\left[\frac{\left(1+\mathrm{E}_{\text {н.п. }}\right)^{n}-1}{\mathrm{E}_{\text {н.п. }}\left(1+\mathrm{E}_{\text {н.п. })^{n}}\right.}\right]=260,9+2,99 \cdot\left[\frac{(1+0,06)^{30}-1}{0,06 \cdot(1+0,06)^{30}}\right]=301 \text { млн. руб. }
$$

где $K$ и $И$ - капиталовложения и издержки в $t$-й год;

$E_{\text {н.п }}-$ ставка дисконтирования, $E_{\text {н.п. }}=0,06$.

\section{Расчет по варианту 2.}

\section{Капиталовложения на установку АББМ}

$$
K_{A Б Б M}=\kappa_{\text {АББМ }} \cdot P_{A Б Б M} \cdot \Delta t \cdot k_{\text {стр }} \cdot k_{\text {рег }} \cdot k_{\mathrm{c}},
$$

где $k_{\text {АББм }}-$ стоимость объекта-аналога АББМ, $k_{\text {АББм }}=8,5$ млн.

руб./МВт ч ч

в ценах 2000 года;

$P_{A Б Б M}-$ мощность АББМ, $P_{A Б Б M}=130 \mathrm{MBT}$;

$\Delta t$ - продолжительность беспрерывного разряда АББМ, $\Delta t=0,2$ ч;

$k_{\text {стр }}-$ коэффициент, учитывающий затраты, сопутствующие строительству: временные здания и сооружения, строительный контроль и др., $k_{\text {стр }}=1,24$ [4];

$k_{\text {рег }}, k_{\mathrm{c}}$ - региональные коэффициенты удорожания строительства и в сейсмических районах соответственно, $k_{\mathrm{per}}=1,09 ; k_{\mathrm{c}}=1,0$ [4],

$K_{\text {АББм }}=8,5 \cdot 130 \cdot 0,2 \cdot 1,24 \cdot 1,09 \cdot 1,0=298,7$ млн. руб.

Ежегодные издержки на ремонт и обслуживание АББМ составляют

$$
И_{\text {АББМ }}=h_{\text {обсл }} \cdot K_{\text {АББм }}=0,05 \cdot 298,7=14,9 \text { млн. руб. }
$$

\section{Дисконтированные затраты по варианту 2}

Дисконтированные затраты определяют по формуле

$$
\begin{gathered}
3_{i}=K+И \cdot\left[\frac{\left(1+\mathrm{E}_{\text {н.п. }}\right)^{n}-1}{\mathrm{E}_{\text {н.п. }}\left(1+\mathrm{E}_{\text {н.п. }}\right)^{n}}\right]=298,7+14,9 \cdot\left[\frac{(1+0,06)^{30}-1}{0,06 \cdot(1+0,06)^{30}}\right]=503,8 \text { млн. } \\
\text { руб. }
\end{gathered}
$$

где $K$ и $И-$ капиталовложения и издержки в $t$-й год;

$$
E_{\text {н.п }}-\text { ставка дисконтирования, } E_{\text {н.п. }}=0,06 \text {. }
$$

Результаты расчетов по вариантам 1 и 2 приведены в таблице 2. 
Таблица 2

Сравнение дисконтированных затрат по вариантам 1 и 2

\begin{tabular}{|c|c|}
\hline Вариант 1 & Вариант 2 \\
\hline $\begin{array}{l}\text { Капиталовложения на строительство } \\
\text { одноцепной ВЛ } 220 \text { кВ: } \\
K_{\text {Вл }}=260,9 \text { млн. руб. } \\
\text { Капиталовложения на установку } \\
\text { дополнительного элегазового выключателя } \\
K_{\mathrm{B}}=18,17 \text { млн. руб. } \\
\text { Суммарные капиталовложения: } \\
K_{1}=279,1 \text { млн. руб. }\end{array}$ & $\begin{array}{l}\text { Капиталовложения в установку АББМ: } \\
K_{2}=K_{\text {АББм }}=298,7 \text { млн. руб. }\end{array}$ \\
\hline $\begin{array}{l}\text { Ежегодные издержки на ремонт и } \\
\text { обслуживание: } \\
И_{\text {Вл }}=2,08 \text { млн. руб.; } \\
И_{П С}=0,91 \text { млн. руб.; } \\
\text { Суммарные ежегодные издержки: } \\
И_{1}=2,99 \text { млн. руб. }\end{array}$ & $\begin{array}{l}\text { Ежегодные издержки на ремонт и } \\
\text { обслуживание АББМ: } \\
И_{2}=И_{\text {АББм }}=0,05 \cdot 298,7=14,9 \text { млн. руб. }\end{array}$ \\
\hline $\begin{array}{l}\text { Дисконтированные затраты: } \\
3_{1}=301 \text { млн. руб. }\end{array}$ & $\begin{array}{l}\text { Дисконтированные затраты } \\
3_{2}=503,8 \text { млн. руб. }\end{array}$ \\
\hline
\end{tabular}

Анализ результатов расчетов, приведенных в таблице 2, показывает, что:

- капитальные вложения на строительство одноцепной ВЛ 220 кВ и установку одного дополнительного элегазового выключателя по варианту 1 меньше на 19,6 млн. руб., чем при установке аккумуляторной батареи большой мощности (АББМ) по варианту 2;

- ежегодные издержки на ремонт и обслуживание ВЛ и ПС также меньше на 11,9 млн. руб. по сравнению с издержками на ремонт и обслуживание АББМ;

- дисконтированные затраты по варианту 2 больше, чем по варианту 1 на 202, 8 млн. руб.. т.е. превышают в 1,5 раза.

Вывод. Вариант усиления сети со строительством новой ВЛ 220 кВ имеет минимальные дисконтированные затраты (301 млн. руб.) и является более предпочтительным. Вариант с установкой АББМ имеет дисконтированные затраты ( $\approx 504$ млн. руб.), в 1,5 раза выше по сравнению с первым вариантом, и, следовательно, установка АББМ нецелесообразна. 


\section{Список литературы}

1. Методические рекомендации по проектированию развития энергосистем / CO 153-34.20.118-2003 // www.cius-ees.ru. - Дата обращения 06.12.2020.

2. Об утверждении требований к обеспечению надежности электроэнергетических систем, надежности и безопасности объектов электроэнергетики и энергопринимающих установок «Методические указания по устойчивости энергосистем» / Приказ Минэнерго России от 03.08.2018 № 630 // http://publicationpravo.gov.ru. - Дата обращения 06.12.2020.

3. Типовые технические требования к трансформаторам, автотрансформаторам (распределительным, силовым) классов напряжения 110 750 кВ / CTO 56947007-29.180.091-2011 // www.fsk-ees.ru. - Дата обращения 06.12.2020.

4. Укрупнённые стоимостные показатели линий электропередачи и подстанций напряжением 35-1150 кВ» 324 тм - т1 для электросетевых объектов / CTO 56947007-29.240.124-2012 // www.fsk-ees.ru. - Дата обращения 06.12.2020.

5. Справочник по проектированию электрических сетей / Под ред. Д.Л. Файбисовича // Москва: Изд-во НЦ ЭНАС. - 2012. - 376 с.

6. Методические указания по технико-экономическому обоснованию электросетевых объектов. Эталоны обоснований / СТО 56947007 29.240.01.271-2019: введ. 24.07.2019 // ПАО «ФСК ЕЭС», 2019. - 33 с.

(C) Андрианова Л.П., Павлова 3.Х., Хакимьянов М.И., Хазиева Р.Т., 2020 